\title{
Effect of Thermal Energy and Ultrasonication on Mixing Efficiency in Passive Micromixers
}

\author{
Fahizan Mahmud ${ }^{1}$, Khairul Fikri Tamrin ${ }^{1, *}$, , Shahrol Mohamaddan ${ }^{2}$ and Nobuo Watanabe ${ }^{2}$ \\ 1 Department of Mechanical and Manufacturing Engineering, Faculty of Engineering, Universiti Malaysia \\ Sarawak (UNIMAS), Kota Samarahan 94300, Sarawak, Malaysia; fahizanmahmud@gmail.com \\ 2 Department of Bioscience and Engineering, College of Systems Engineering and Science, Shibaura Institute \\ of Technology, Fukasaku 307, Minuma-ku, Saitama 337-8570, Japan; mshahrol@shibaura-it.ac.jp (S.M.); \\ nobuo@sic.shibaura-it.ac.jp (N.W.) \\ * Correspondence: tkfikri@unimas.my; Tel.: +60-11-1565-3090; Fax: +60-8258-3410
}

check for updates

Citation: Mahmud, F.; Tamrin, K.F.; Mohamaddan, S.; Watanabe, N. Effect of Thermal Energy and Ultrasonication on Mixing Efficiency in Passive Micromixers. Processes 2021, 9, 891. https://doi.org/ $10.3390 /$ pr9050891

Academic Editor: Jianhong Xu

Received: 24 April 2021

Accepted: 15 May 2021

Published: 18 May 2021

Publisher's Note: MDPI stays neutral with regard to jurisdictional claims in published maps and institutional affiliations.

Copyright: (c) 2021 by the authors. Licensee MDPI, Basel, Switzerland. This article is an open access article distributed under the terms and conditions of the Creative Commons Attribution (CC BY) license (https:// creativecommons.org/licenses/by/ $4.0 /)$.

\begin{abstract}
Micromixing is a key process in microfluidics technology. However, rapid and efficient fluid mixing is difficult to achieve inside the microchannels due to unfavourable laminar flow. Active micromixers employing ultrasound and thermal energy are effective in enhancing the micromixing process; however, integration of these energy sources within the devices is a non-trivial task. In this study, ultrasound and thermal energy have been extraneously applied at the upstream of the micromixer to significantly reduce fabrication complexity. A novel Dean micromixer was laserfabricated to passively increase mixing performance and compared with T- and Y-micromixers at Reynolds numbers between 5 to 100. The micromixers had a relatively higher mixing index at lower Reynolds number, attributed to higher residence time. Dean micromixer exhibits higher mixing performance (about $27 \%$ better) than T- and Y-micromixers for $40 \leq \mathrm{Re} \leq 100$. Influence of ultrasound and heat on mixing is more significant at $5 \leq \operatorname{Re} \leq 20$ due to the prolonged mechanical effects. It can be observed that mixing index increases by about $6 \%$ to $10 \%$ once the temperature of the sonicated fluids increases from $30^{\circ} \mathrm{C}$ to $60^{\circ} \mathrm{C}$. The proposed method is potentially useful as direct contact of the inductive energy sources may cause unwanted substrate damage and structural deformation especially for applications in biological analysis and chemical synthesis.
\end{abstract}

Keywords: microfluidics; micromixer; ultrasound; thermal; dean flow

\section{Introduction}

Microfluidics is an evolving field, with applications providing significant control and manipulation of fluids within the microenvironment $[1,2]$. Micromixing is the backbone of microfluidic devices for the applications of reagents and analytes detection, drug screening, diseases diagnosis and various fluidic operations at microscale [3-5]. The micromixing characteristics of microfluidics are contrary to mechanical mixing in which the latter falls in a turbulence regime, whereas the former is associated with laminar regime as a consequence of miniaturized feature of microchannel having hydraulic diameters of less than several hundred microns.

Micromixing can be divided into two distinguishable mixing principles, namely active and passive mixing [2,6]. Of many active mixing mechanisms, ultrasound and thermal energies are the two common modes of inductive external source for creating fluid disturbance in micromixers. Ultrasound has been reported as an effective means to enhance mixing performance in microfluidics [7-9]. This is because the dissipated ultrasound energy induced acoustic streaming from the formation of intensified macroscopic liquid flow [7]. The mechanical effect due to acoustic streaming was shown to be effective in improving mixing at significantly higher flow rates [7]. Yang et al. [9] directly introduced ultrasonic vibration using $60 \mathrm{kHz}$ piezoelectric ceramic to create turbulence during relatively fast micromixing between a uranine solution and water. Similarly, thermal energy was found 
effective in enhancing micromixing as the fluid viscosity reduces with the increase of temperature, thereby promoting greater molecular diffusion $[10,11]$.

Passive mixing is the preferred mixing mechanism due to its ease of fabrication and non-reliance on external energy. The absence of turbulent flow in the micromixers poses a challenge to completely mix the fluids as the mixing dominantly depends on molecular diffusion [12-14]. Since turbulent flow is seldom achieved, mass transfer by molecular diffusion can be enhanced by increasing either residence time or contact surface between the mixing fluids. Longer residence time can be achieved by geometrical manipulation $[15,16]$ and reduced fluid flow rate $[17,18]$, while larger mixing interface can be achieved by introducing Dean vortices (secondary flow) inside the microchannel [19,20]. Various designs of passive micromixer have been studied in the past, including chaotic advection-based and lamination-based micromixers [21]. Using chaotic advection-based micromixer, Parsa et al. [19] demonstrated enhanced mixing performance in a sinusoidal convergent-divergent microchannel due to the effect of combined Dean and separation vortices especially at $\operatorname{Re}>20$. Ansari et al. [20] studied unbalanced split and recombination lamination-based micromixer on the basis of unequal Dean number for varying Reynolds number of $10 \leq \operatorname{Re} \leq 80$, and the outcome of the mixing performance is relatively higher than that of balanced micromixers. The enhanced mixing can be attributed to the unbalanced collision of two fluid streams which causes perturbed and shifted mixing fluid interface inside the mixing junction.

Although passive mixing is preferable due to simple mixing principle, their mixing performance is lower and more difficult to control compared to an active micromixer [2].

In spite of that, active mixing mechanisms also have their own limitations. For instance, magnetic force induced mixing usually requires utilization of ferrofluid [22] to create disturbance inside the fluidics system, which is undesirable especially for DNA purification process $[23,24]$. Furthermore, additional actuating mechanisms employing i.e., magnetic beads or magnetic artificial cilia [25] increases system complexity. Active micromixers utilizing ultrasound and thermal energy have been demonstrated effective to enhance micromixing process. Luong et al. [26] fabricated interdigitated electrodes for concentrating the remotely introduced acoustic energy through manipulation of applied voltage and frequency, while Yaralioglu et al. [27] demonstrated acoustic stirring by means of embedded piezoelectric transducers. Nevertheless, integration of these mechanisms within the devices is a non-trivial task $[9,11,26,27]$. Similarly, Bezagu et al. [28] utilized a remotely focused ultrasound to induce vaporization of perfluorocarbon phase at varying acoustic pressure (in $\mathrm{MPa}$ ) and intensity of the focused wave (in Watt $/ \mathrm{cm}^{2}$ ). Acoustically driven sidewall-trapped microbubbles [29] also showed encouraging utilization of ultrasound in mixing enhancement. Meng et al. [30] found that the micromixing performance can be enhanced at relatively higher temperatures by increasing the applied AC voltages through four arc-electrodes. In a different study, Huang et al. [31] also demonstrated a higher mixing efficiency utilizing electrothermal heating as compared to passive mixing using diffusive and convective obstacles. However, the direct contact of the energy sources may cause substrate damage and structural deformation [32]. To the best of our knowledge, there is no publishable work combining passive Dean micromixer with extraneously induced ultrasound and thermal energy to enhance mixing performance, which is the primary aim of this study. Here, a Dean micromixer was laser-fabricated, and its mixing performance was compared with wellknown T- and Y- micromixers at different Reynolds numbers $(5 \leq \mathrm{Re} \leq 100)$. The proposed ultrasound and thermal energy were applied extraneously at the upstream of the micromixer to significantly reduce fabrication complexity, and their effects on mixing performance were also investigated. The experiment is described in the following section.

\section{Materials and Methods}

\subsection{Mixing Quantification}

Mixing performance is usually determined using homogeneity information of the mixing images $[15,17,33-35]$ at the expense of overestimated or underestimated mixing 
index. To overcome this, an optical method based on RGB colour model was employed to compute the mixing index [36]. This method considers each pixel inside the mixing image by decoding their red, green and blue (RGB) values as follows:

$$
\text { Mixing index }=\mathrm{N}_{\text {mixed }} /\left(\mathrm{N}_{\text {mixed }}+\mathrm{N}_{\text {unmixed }}\right)
$$

where $\mathrm{N}_{\text {mixed }}$ and $\mathrm{N}_{\text {unmixed }}$ are the number of pixels for mixed and unmixed solution, respectively, computed using the following equations:

$$
\mathrm{N}_{\text {mixed }}=\mathrm{n}\left(\left\{\mathrm{r}_{\mathrm{g}, \text { min }} \leq \mathrm{R} \leq \mathrm{r}_{\mathrm{g}, \text { max }} \cap \mathrm{g}_{\mathrm{g}, \text { min }} \leq \mathrm{G} \leq \mathrm{g}_{\mathrm{g}, \max } \cap \mathrm{b}_{\mathrm{g}, \min } \leq \mathrm{B} \leq \mathrm{b}_{\mathrm{g}, \max }\right\}\right)
$$

and

$$
\begin{gathered}
N_{\text {unmixed }}=n\left(\left\{r_{b, \min } \leq R \leq r_{b, \max } \cap g_{b, \text { min }} \leq \mathrm{G} \leq \mathrm{g}_{\mathrm{b}, \max } \cap \mathrm{b}_{\mathrm{b}, \min } \leq \mathrm{B} \leq \mathrm{b}_{\mathrm{b}, \max }\right\}\right) \\
+\mathrm{n}\left(\left\{\mathrm{r}_{\mathrm{y}, \min } \leq \mathrm{R} \leq \mathrm{r}_{\mathrm{y}, \max } \cap \mathrm{g}_{\mathrm{y}, \min } \leq \mathrm{G} \leq \mathrm{g}_{\mathrm{y}, \max } \cap \mathrm{b}_{\mathrm{y}, \min } \leq \mathrm{B} \leq \mathrm{b}_{\mathrm{y}, \max }\right\}\right)
\end{gathered}
$$

where number of detected pixels within the range of RGB values is denoted by $n$ and $\cap$ is the AND Boolean operator. The extracted minimum/maximum RGB values are represented by $r, g$ and $b$. The representative green, blue and yellow pixels are denoted by subscripts $\mathrm{g}, \mathrm{b}$ and $\mathrm{y}$, respectively. A mixing index of 0 or 1 represents unmixed and fully mixed solutions, respectively. It is noted that the reference RGB values in Equations (2) and (3) are discussed in Section 3.1.

\subsection{Micromixer Fabrication}

Figure 1a shows a schematic diagram of the proposed Dean micromixer design utilizing unbalanced collision of Dean vortices at the inlet channels. The magnitude of the Dean vortices is directly related to the Reynolds number and is described by the following equation:

$$
\mathrm{De}=\operatorname{Re}\left(\mathrm{D}_{\mathrm{h}} / 2 \mathrm{R}_{\mathrm{c}}\right)^{1 / 2}
$$

where De is the Dean number, $D_{h}$ hydraulic diameter of channel and $R_{c}$ is the radius of curvature of the curved path. By referring to Equation (4), a decrease in the radius of curvature will increase the Dean number while the effect of $R_{c}$ towards Dean number is twice of that $D_{h}$. The optimum ratio of Dean number is 1.414 as reported by Ansari et al. [20]. In this study, a similar concept of unbalanced Dean numbers with the same Dean number ratio was employed for the inlet channels by manipulating the inlets' radius of curvature. For meaningful comparison and benchmarking purposes, performance of Dean micromixer, in term of the mixing index was evaluated and compared with well-known T- and Ymicromixer designs $[7,15,17,37]$, as shown in Figure $1 \mathrm{~b}, \mathrm{c}$, respectively. Point A has been selected by taking into consideration the characteristic length, LC of the microchannel:

$$
\mathrm{L}_{\mathrm{C}}=\mathrm{L} / \mathrm{D}_{\mathrm{h}}
$$

where $L$ denotes the distance of the measurement point from the junction of the microchannel. The selected point $A$ (indicated by $\mathrm{L}_{\mathrm{A}}$ in Figure 1a) with $\mathrm{L}_{\mathrm{C}}=32.5$ is approximately similar to the previously conducted study by You et al. [14] with $\mathrm{L}_{\mathrm{C}}=33.3$. As shown in Figure 1, point $B\left(L_{C}=97.5\right)$ was set to be three times $L_{C}$ of point $A$, and used to compute the mixing index downstream of the microchannel [38]. Point $B$ is indicated by $L_{B}$ in Figure 1a.

Figure 2 illustrates the procedures to fabricate the micromixers using lamination film (200 $\mu \mathrm{m}$ thickness), double-sided adhesive film [39] (100 $\mu \mathrm{m}$ thickness) and PMMA sheet ( $3 \mathrm{~mm}$ thickness) as the main components. The central part which consists of lamination film, sandwiched in between two adhesive films was laser cut using a $\mathrm{CO}_{2}$ laser (Model: Fabool, smartDIYs Inc., Tennessee, Japan). Laser micromachining process was selected because it provides great advantages over other method in term of fabrication time and cost, although some complex 3D microchannel designs are difficult to fabricate using this method [40,41]. 
The laser was set with parameters of $1.2 \mathrm{~W}$ power, $150 \mathrm{~mm} / \mathrm{s}$ speed, $50.8 \mathrm{~mm}$ focal distance and three laser passes to construct the microchannels. The measured dimension of the channel is approximately $250 \mu \mathrm{m}$. A PMMA sheet was attached on top of the central part to increase the micromixer structural rigidity. To compensate for flatness irregularities, an additional lamination film was glued to the base of the micromixer. It is noted that the same laser was used to produce $5 \mathrm{~mm}$ holes for two inlets and one outlet on the PMMA sheet prior to the final assembly, with laser parameters of $40 \mathrm{~W}$ power, $500 \mathrm{~mm} / \mathrm{s}$ speed, $50.8 \mathrm{~mm}$ focal distance and single laser pass. These ports were connected to transparent tubes of $3 \mathrm{~mm}$ internal diameter using 3D printed connector. UV acrylic resin was used to prevent any leakage at the ports. Figure 3 shows the fabricated T-, Y- and Dean micromixers.

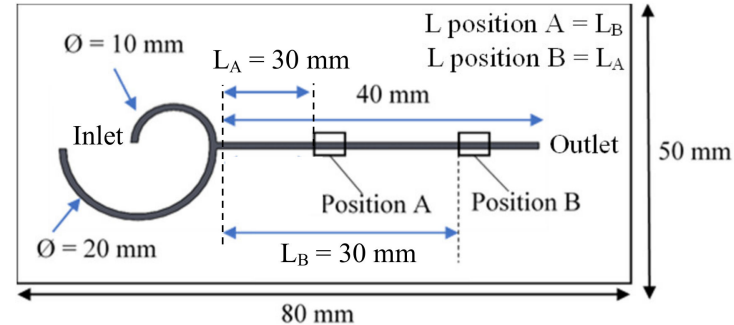

(a)

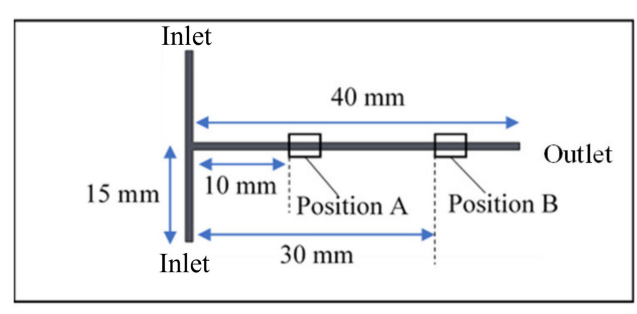

(b)

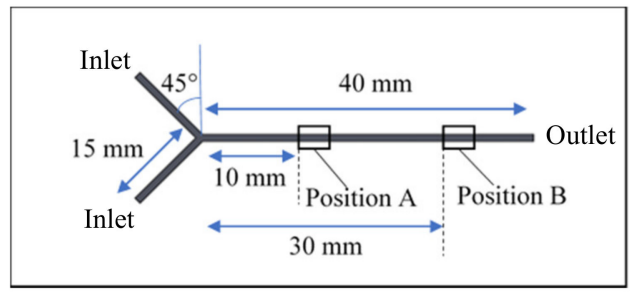

(c)

Figure 1. Structure of the designed micromixers and the points of measurements (A and B) (a) Proposed Dean micromixer (b) T-micromixer (c) Y-micromixer.

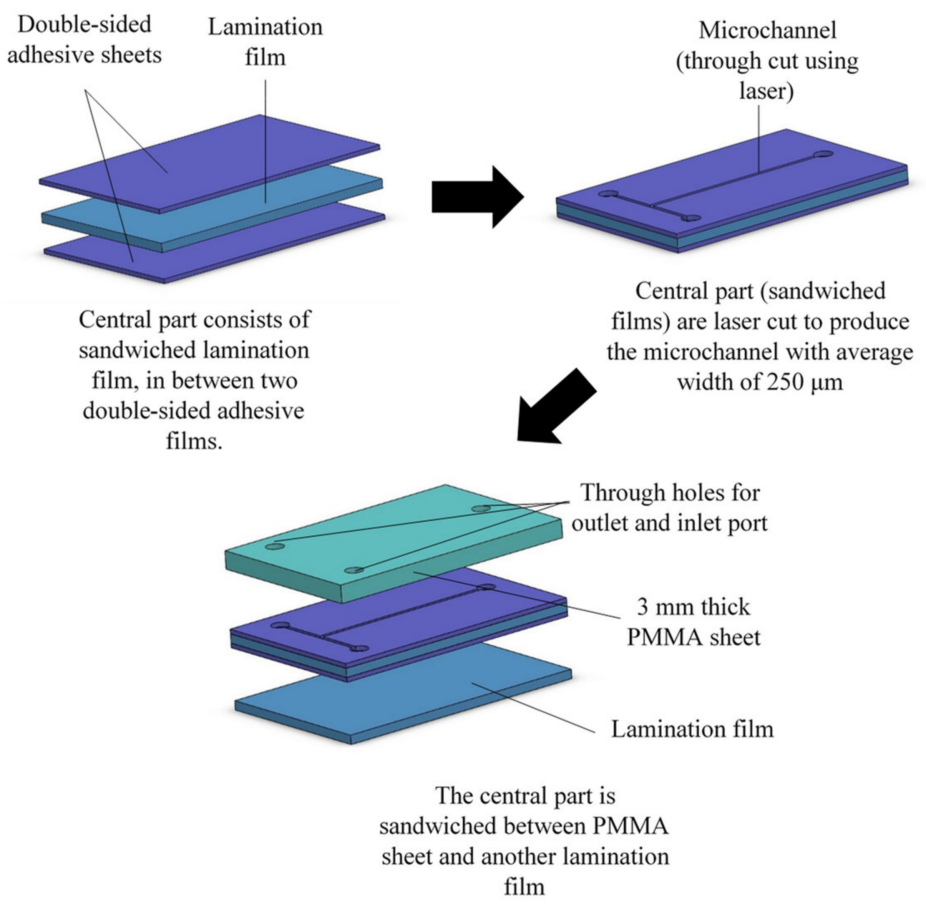

Figure 2. Steps in fabricating micromixers. 


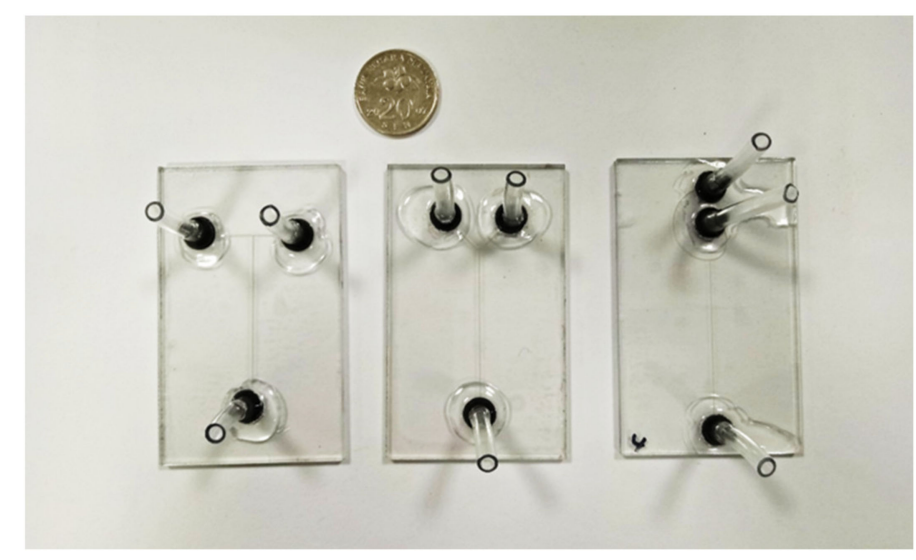

Figure 3. Fabricated T-, Y- and Dean micromixers.

\subsection{Experimental Setup}

Figure 4 shows a schematic diagram of an experimental setup, which includes a micromixer, digital video microscope, fluid driving mechanism and ultrasonic tank with temperature control. 3D printer was used to fabricate a dual syringe pump to drive two streams of coloured solutions into the separate inlet arms of T-, Y- and Dean micromixers with an equal flow rate. Food grade dyes were diluted with deionized water with ratio of 1:25 to produce these yellow and blue coloured solutions. The viscosity and density of the coloured solutions are assumed similar to deionized water. The coloured solutions inside both syringes were driven by a NEMA 17 stepper motor, connected with a lead screw and guided with two steel rods. A4988 motor driver was used to drive the stepper motor, and Arduino UNO as the controller. The A4988 motor driver was used to increase the resolution step from 200 to 3200 for a single rotation. Additionally, the dual syringe pump system was connected with a DC power supply (GPS-3030D, Good Will Instrument Co., Ltd., New Taipei City, Taiwan). Image acquisition was performed at $4 \times$ magnification using a digital video microscope (MD500, AmScope, Irvine, CA, USA). The captured mixing images were post-processed using MATLAB software to compute their respective mixing indices using Equation (1). The schematic diagram for the experimental setup is shown in Figure 5.

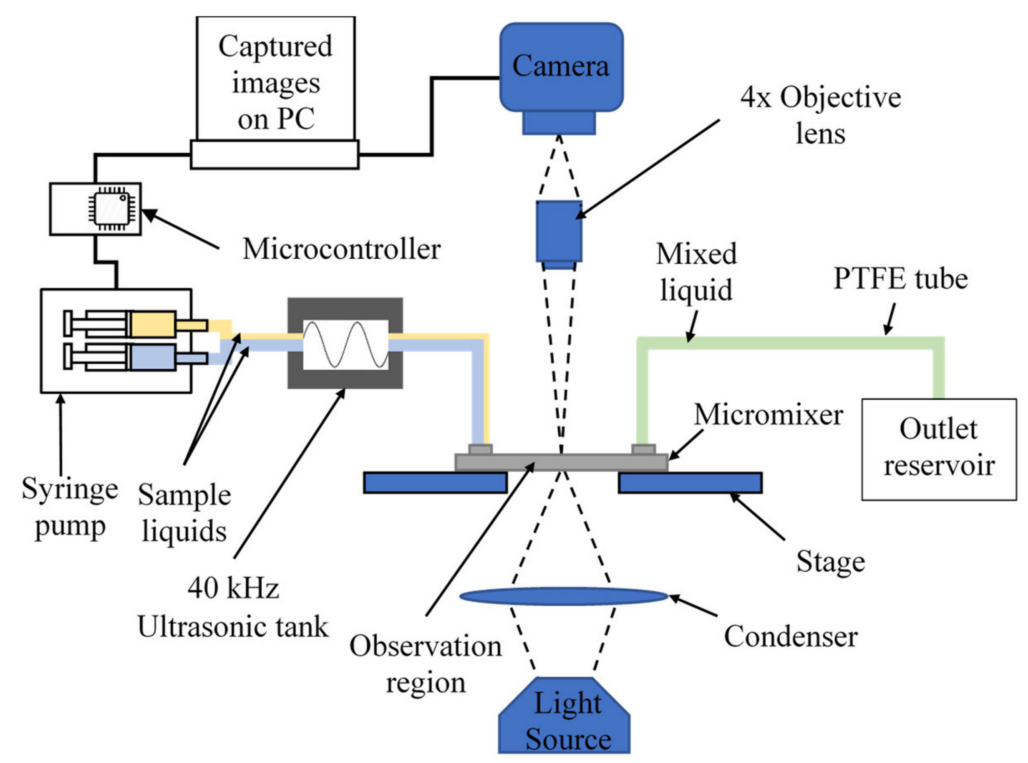

Figure 4. Schematic diagram of the micromixing experiment. 


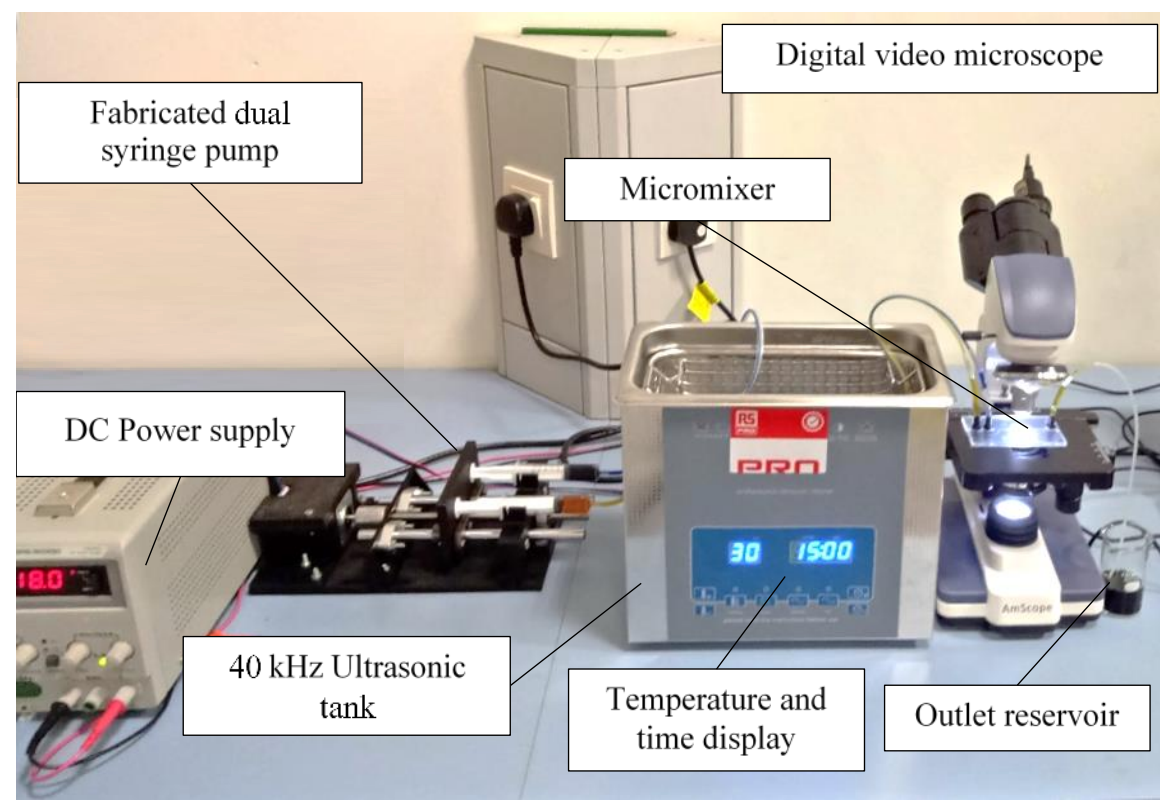

Figure 5. Experimental setup of the micromixing experiment.

Firstly, the effect of extraneously induced excitation due to ultrasound towards mixing index was carried out by immersing $40 \mathrm{~cm}$ length PVC tube inside the ultrasonic tank (Model: SHE-UT8031-EUK, RS Components Ltd., Kwai Chung, Hongkong). Secondly, the heating element inside the same ultrasonic tank was regulated to investigate the effect of both ultrasound and thermal energy on mixing performance. In all of the studies conducted, the mixing indices were measured at the Reynolds numbers ranging from 5 to 100 . For comparison purposes, the mixing indices were measured at two measurement points as shown in Figure 1.

\section{Results and Discussion}

A novel passive Dean micromixer based on the concept of unbalanced Dean vortices was proposed and fabricated by means of laser micromachining process. Experimental analysis was performed to investigate the mixing index at different flow rates, varied between $5 \leq \operatorname{Re} \leq 100$. Initially, mixing indices of the fabricated Dean micromixer was benchmarked against T- and Y-micromixers. Then, the effects of extraneously ultrasoundinduced excitation (sonication) and thermal energy on mixing index were evaluated.

\subsection{Preliminary Experiment}

As described in Equations (2) and (3), maximum and minimum RGB values were determined prior to computing the mixing index in Equation (1). These values were experimentally obtained by decoding captured images of the solutions inside the microchannel to their respective RGB pixel intensities, as listed in Table 1.

Table 1. Specified RGB values for unmixed and mixed solutions.

\begin{tabular}{cccc}
\hline & Red (R) & Green (G) & Blue (B) \\
\hline $\begin{array}{c}\text { Unmixed Blue } \\
\text { Coloured Solution }\end{array}$ & $\mathrm{R} \geq 0$ and $\mathrm{R} \leq 19$ & $\mathrm{G} \geq 42$ and $\mathrm{G} \leq 100$ & $\mathrm{~B} \geq 50$ and $\mathrm{B} \leq 156$ \\
$\begin{array}{c}\text { Unmixed Yellow } \\
\text { Coloured Solution } \\
\begin{array}{c}\text { Mixed Green } \\
\text { Coloured Solution }\end{array}\end{array}$ & $\mathrm{R} \geq 59$ and $\mathrm{R} \leq 136$ & $\mathrm{G} \geq 50$ and $\mathrm{G} \leq 131$ & $\mathrm{~B} \geq 0$ and $\mathrm{B} \leq 8$ \\
\hline
\end{tabular}




\subsection{Comparison of Mixing Index between T-, Y-and Dean Micromixers}

Qualitative experimental mixing images for T-, Y- and Dean micromixers along the straight microchannels are presented in Figures 6-8, respectively. Initially, the two dissimilar fluids underwent mixing at the junction before flowing into the straight mixing channel. A distinctive narrow region of mixed solution (green coloured) can be observed along the straight microchannel. Mixing index at position B is higher in comparison to position A due to enhancement of mixing behaviour as the fluids flow downstream [35,42]. It can be observed that the mixing occurred the most at the centre of the microchannel due to symmetrical nature of the channel contributed by diffusive mixing mechanism [43].

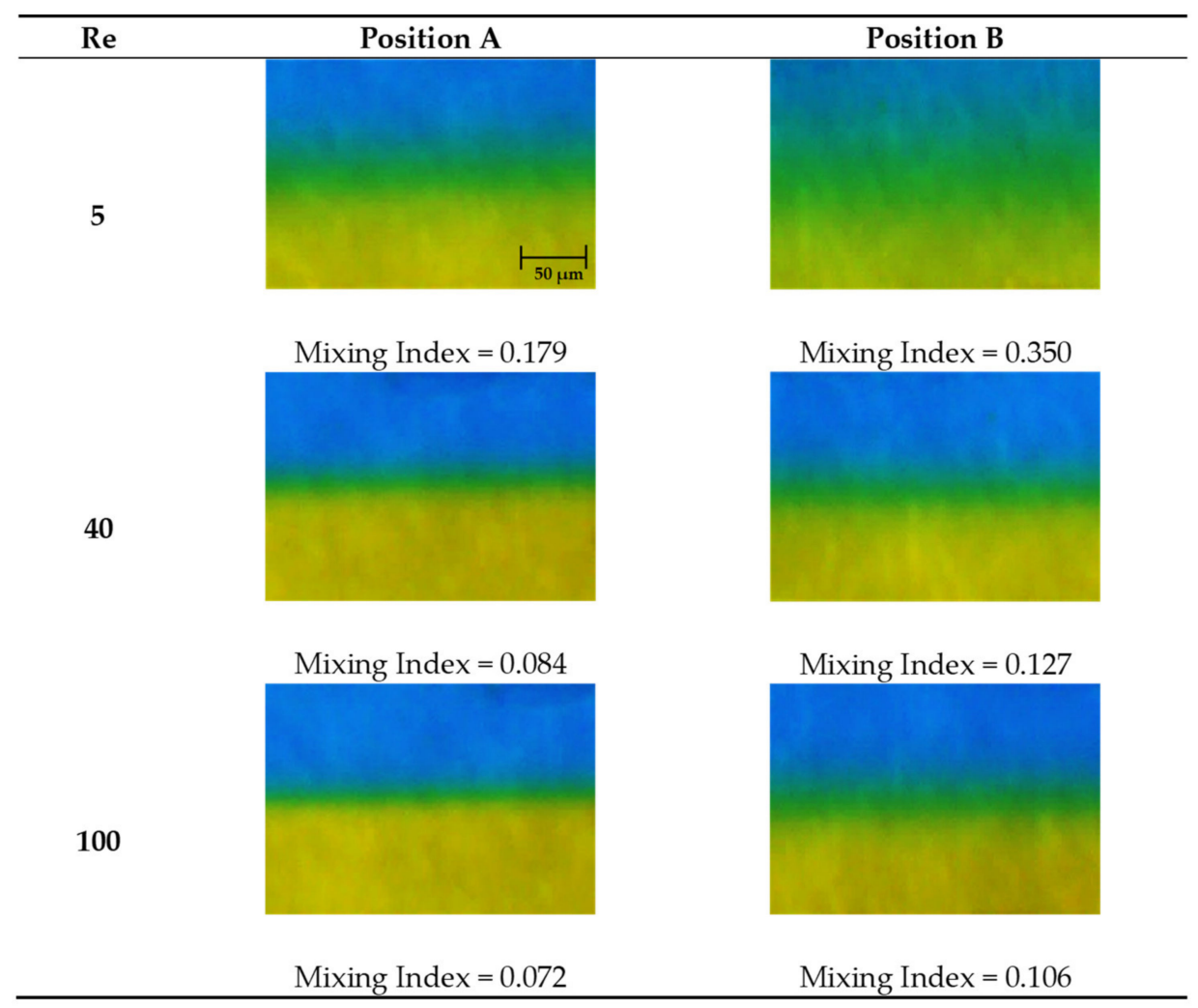

Figure 6. Captured mixing images and mixing index of T-micromixer for $\operatorname{Re}=5,40$ and 100 (Image Size: $250 \times 174 \mu \mathrm{m}^{2}$ ).

Figure 9 compares quantitative mixing indices of T-, Y- and Dean micromixers at position $\mathrm{B}$ for $5 \leq \operatorname{Re} \leq 100$ in the absence of ultrasonic excitation and thermal energy. Three mixing indices of T-micromixer for $\mathrm{Re}=5$ at room temperature have been computed $(\mathrm{MI}=0.3501,0.3505$ and 0.3492$)$. The average value and standard deviation for the sample are 0.3499 and 0.00067 , respectively. Because the standard deviation is insignificant, only one measurement was taken for each Reynolds number at different operating conditions [36]. A clearly similar mixing trend can be observed irrespective of the inlet geometrical designs, as the mixing enhances with a decreasing Reynolds number. All three micromixers have a relatively higher mixing index at a lower Reynolds number attributed to increased molecular diffusion due to higher residence time [44]. This corroborates well with the findings reported in $[45,46]$ for $\operatorname{Re}<150$. 


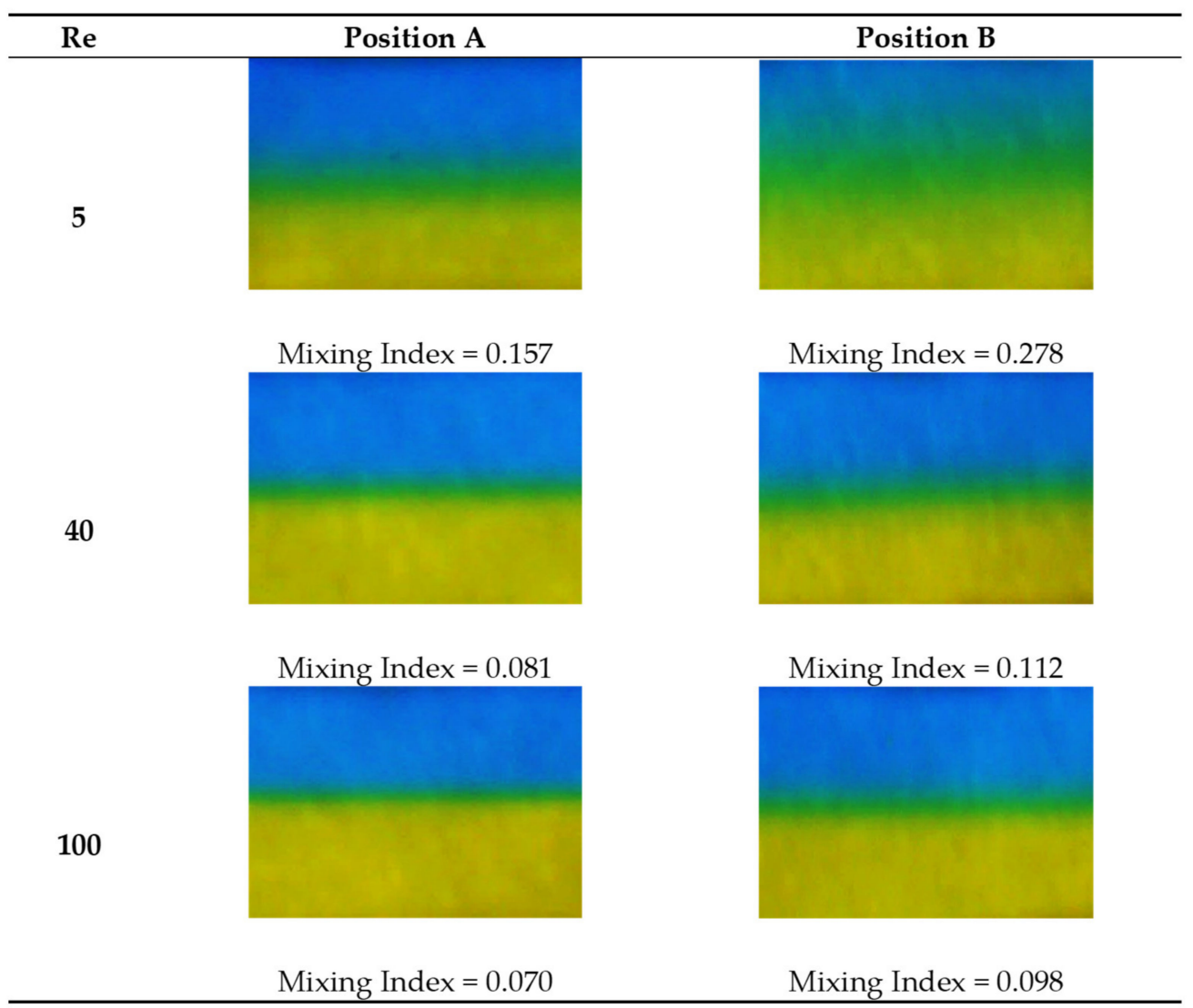

Figure 7. Captured mixing images and mixing index of Y-micromixer for $\operatorname{Re}=5,40$ and 100 (Image Size: $\left.250 \times 174 \mu \mathrm{m}^{2}\right)$.

It is noted that the T-micromixer demonstrates marginally higher mixing performance as compared to $Y$ - and Dean micromixers for $5 \leq R e \leq 20$. This is because the effect of molecular diffusion is more pronounced than the effect of Dean flows. In the curved microchannel (see Figure 1a), higher velocity magnitude at the channel centre has the tendency to move outward of curvature, creating a radial pressure gradient. Because of this centrifugal pressure gradient, the more stagnant fluid at near-wall region would recirculate inward, forming two counter-rotating vortices called Dean vortices with different magnitude depending on the microchannel radius of the curvature [47]. Hence, fluids originating from two dissimilar geometrical inlets having different Dean numbers causes an unbalanced collision of the secondary flow (Dean vortices), and the Dean effect on mixing index becomes more significant at $\operatorname{Re}>20$ [20,47]. This agrees well with the earlier study by Shah et al. [17] who found that the effects of Dean number on mixing is more apparent at higher Reynolds number since Dean number is proportional to Reynolds number (see Equation (4)). For this reason, the Dean micromixer exhibits higher mixing performance (about $27 \%$ better) than the T- and Y- micromixers for $40 \leq \operatorname{Re} \leq 100$. 


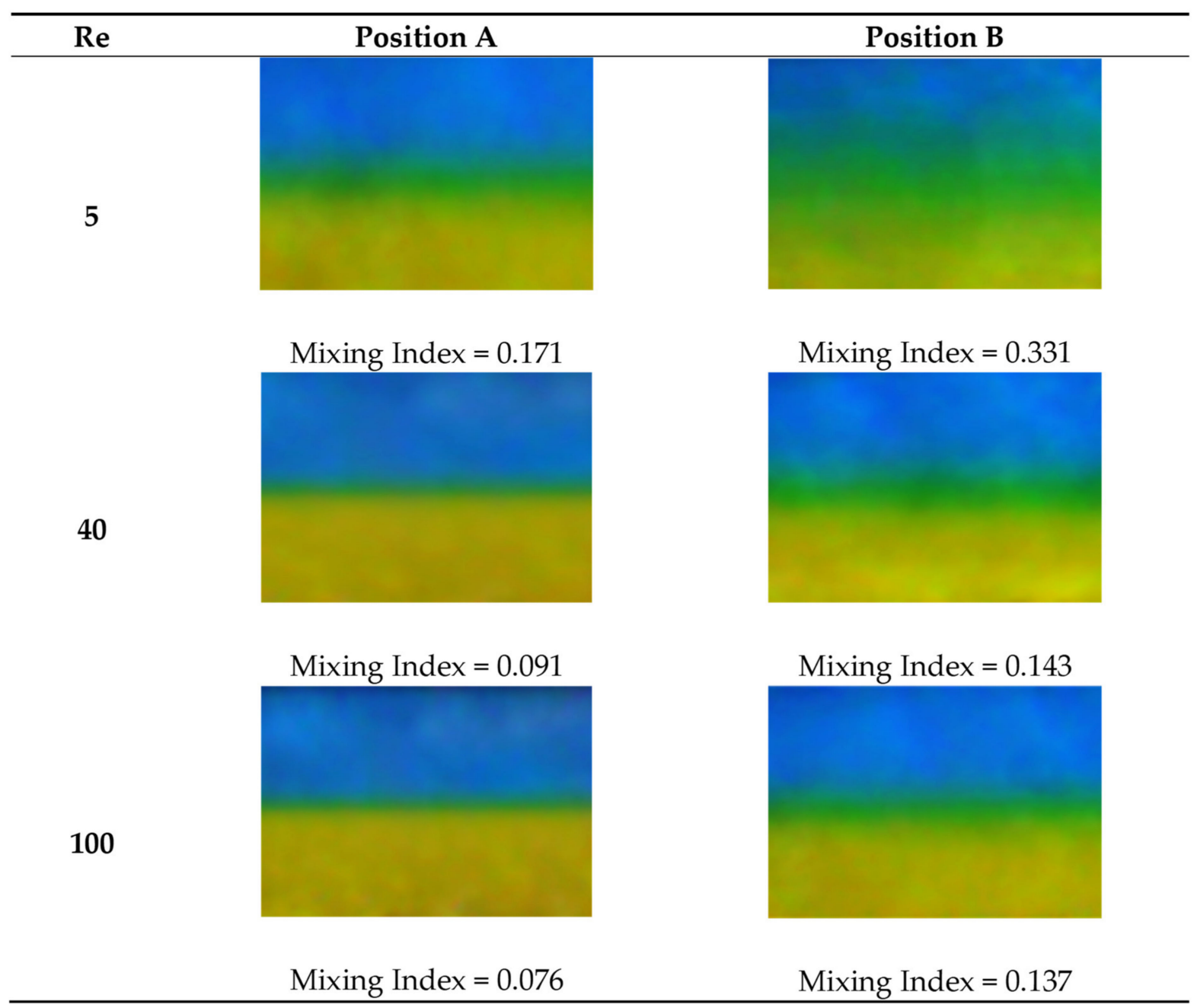

Figure 8. Captured mixing images and mixing index of Dean micromixer for Re = 5, 40 and 100 (Image Size: $250 \times 174 \mu \mathrm{m}^{2}$ ).

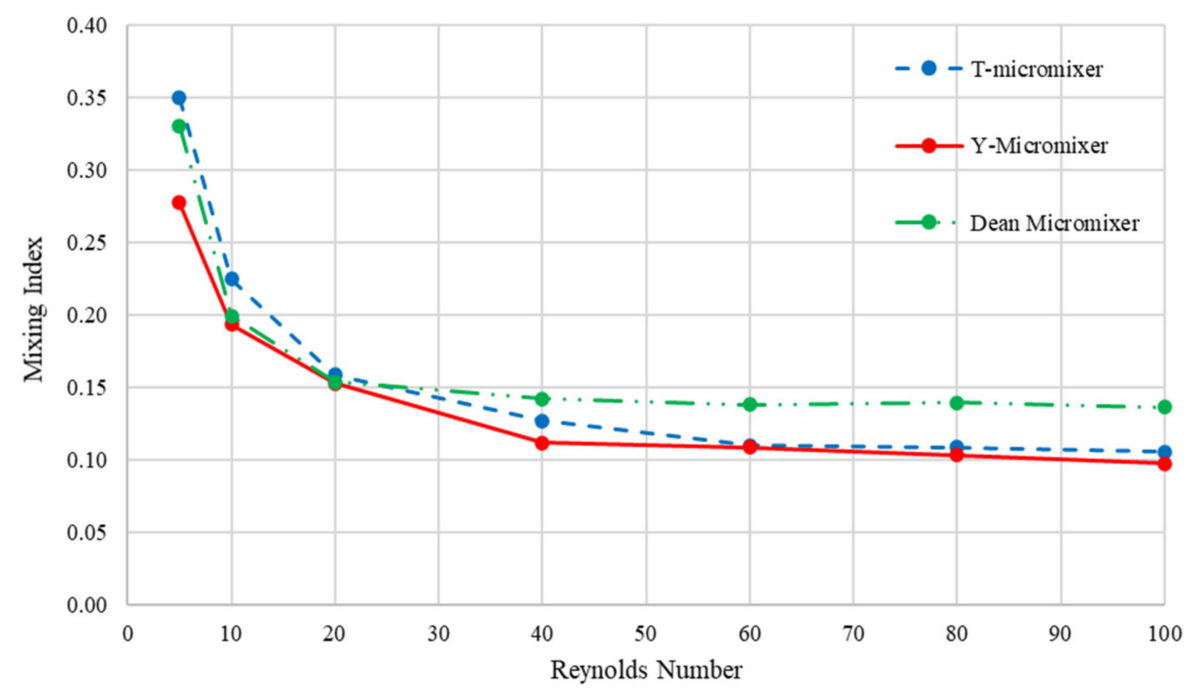

Figure 9. Mixing index of T-, Y- and Dean micromixer for $5 \leq \operatorname{Re} \leq 100$ at position B.

3.3. Comparison of Mixing Index between T-, Y-and Dean Micromixers Due to the Influence of Thermal Energy and Ultrasonication

In the previous experiment, the working fluid temperature was maintained at $25^{\circ} \mathrm{C}$. However, ultrasonic wave propagation resulted in a temperature increase in the fluid [48], 
and therefore the fluid temperature was maintained at $30{ }^{\circ} \mathrm{C}$ for determining the sole effect of ultrasound toward mixing index. The combined ultrasound and thermal effects were subsequently studied at a temperature of $60^{\circ} \mathrm{C}$. It is assumed negligible losses of ultrasound energy and heat energy as the fluid moving from the source to the interrogation point. Qualitative images of the experimental results for Dean micromixers subjected to $40 \mathrm{kHz}$ ultrasound at $30^{\circ} \mathrm{C}$ and $60^{\circ} \mathrm{C}$ are presented in Figures 10 and 11, respectively.

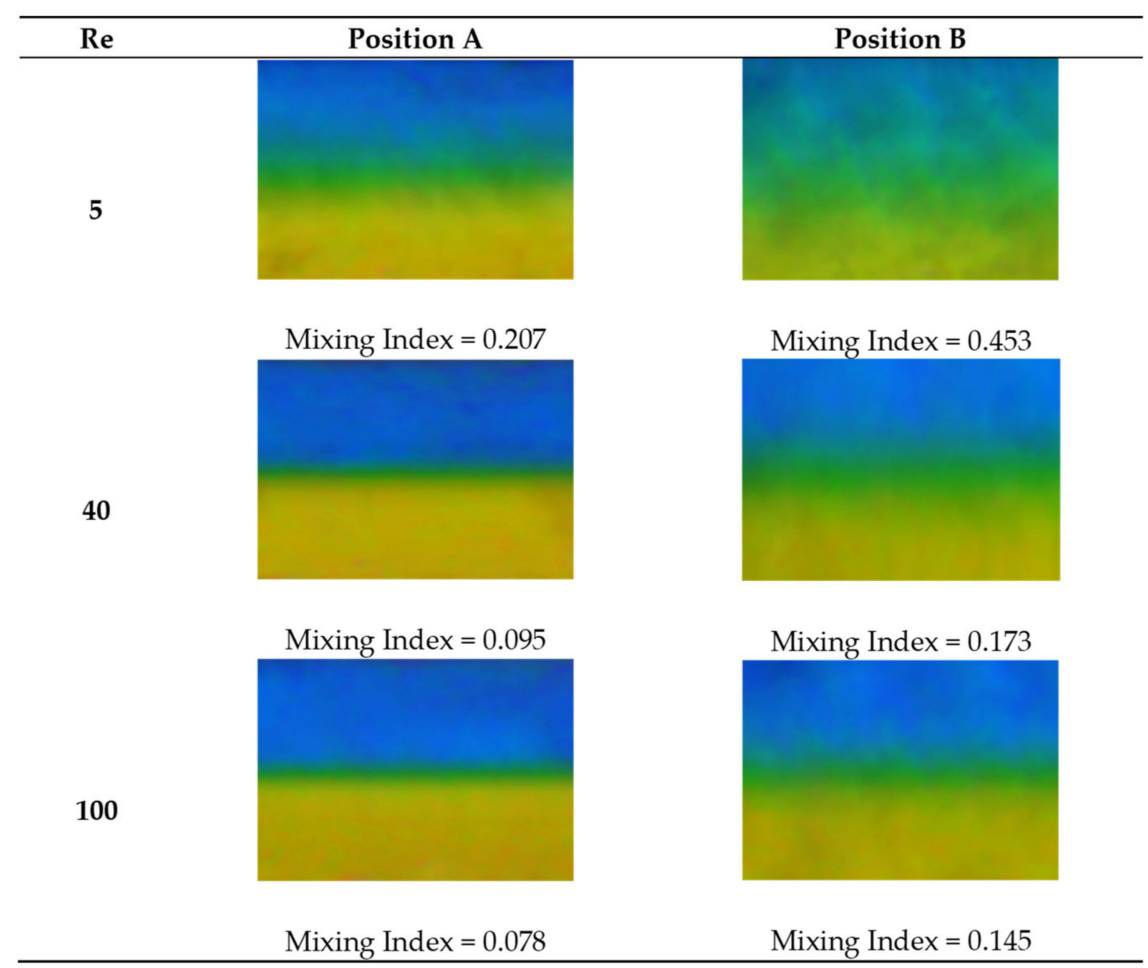

Figure 10. Captured mixing images and mixing index of Dean micromixer using $40 \mathrm{kHz}$ ultrasound and $30{ }^{\circ} \mathrm{C}$ for $\operatorname{Re}=5,40$ and 100 (Image Size: $250 \times 174 \mu \mathrm{m}^{2}$ ).

The experimental results for mixing indices at different operating conditions for the Dean micromixer are shown in Figure 12. It can be observed that the mixing index increases with the decrease of Re. The highest mixing index for varying Reynolds number $(5 \leq \operatorname{Re} \leq 100)$ can be attained under the influence of both ultrasound and thermal energies, followed by ultrasound energy only. This can be attributed to the formation of strong microjets and micro-streams caused by the collapse of microbubbles due to cavitation developed from the ultrasonic wave propagation (sonication) [32]. Furthermore, a phenomenon known as acoustic streaming, which is a convective and macroscopic flow was generated by energy gradient from absorption of acoustic energy during the passage of acoustic wave $[7,49]$. Acoustic streaming is favourable as it enhances micromixing by providing micro agitation inside the liquid phase [32,50]. Additionally, temperature rise reduces fluids viscosity allowing the Dean vortices to retain their hydrodynamic identity longer for enhanced molecular diffusion [32].

It can be observed that the ultrasound and thermal effects on mixing performance is more significant at $5 \leq \operatorname{Re} \leq 20$ because of increased residence time [7,11]. Due to increased residence time, the external energies transmitted responsible for the mechanical effects within the system are prolonged, increasing mass transfer between these mixing fluids [50]. It has also been found that the mixing index increased by about $6 \%$ to $10 \%$ at various Reynolds numbers once the sonicated mixing fluids were heated from $30{ }^{\circ} \mathrm{C}$ to $60{ }^{\circ} \mathrm{C}$. 


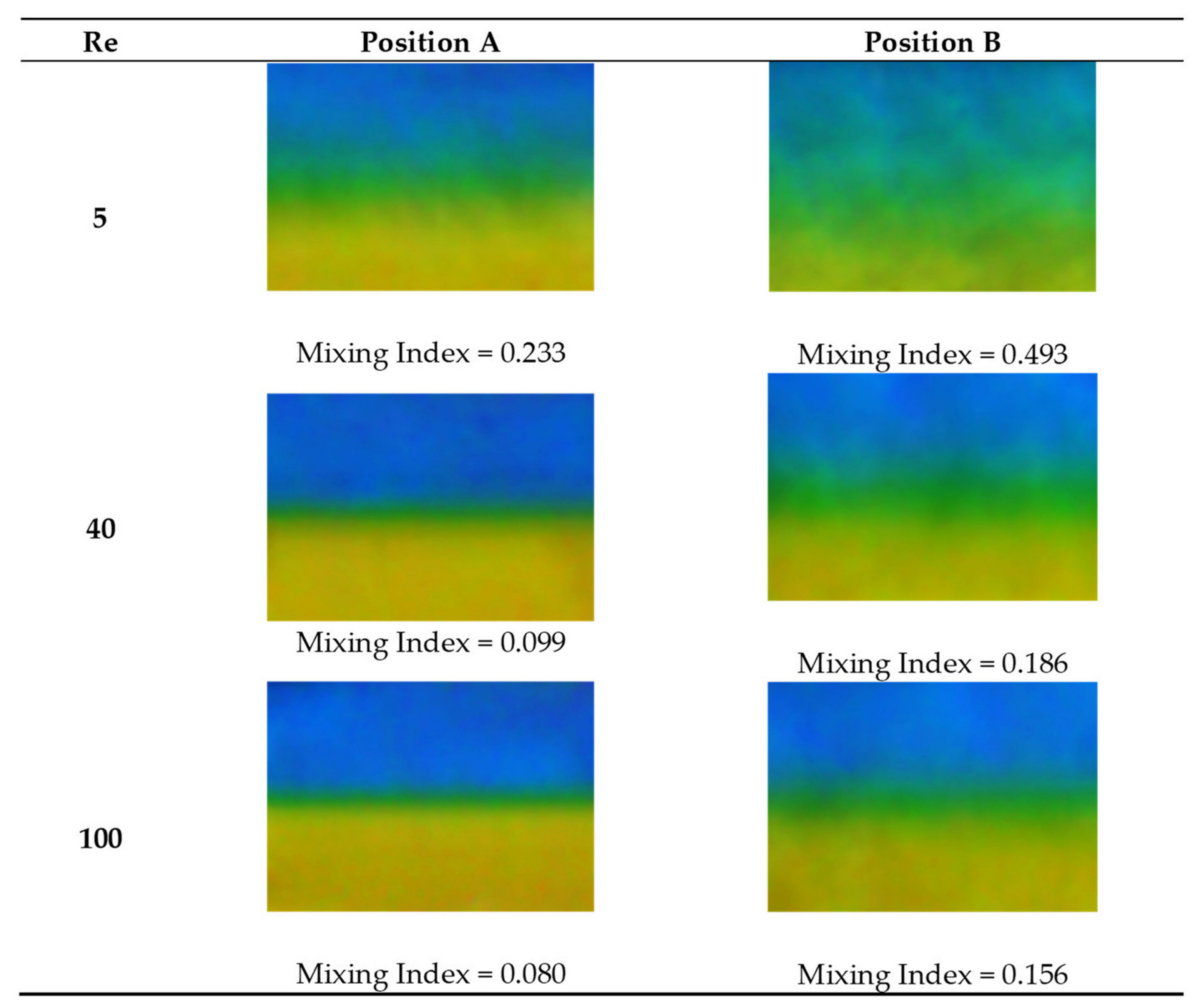

Figure 11. Captured mixing images and mixing index of Dean micromixer using $40 \mathrm{kHz}$ ultrasound and $60{ }^{\circ} \mathrm{C}$ for $\operatorname{Re}=5,40$ and 100 (Image Size: $250 \times 174 \mu \mathrm{m}^{2}$ ).

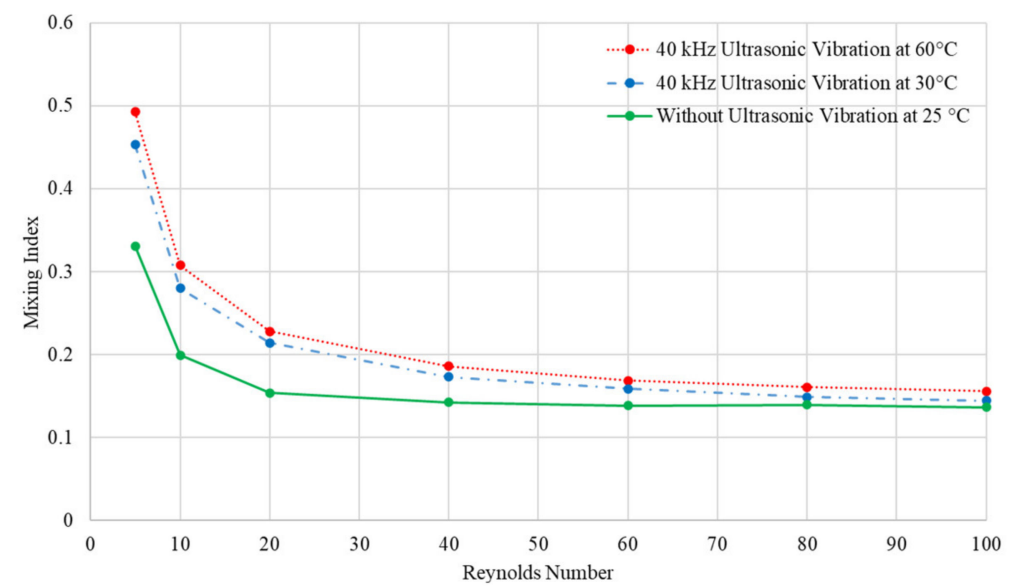

Figure 12. Mixing index of Dean micromixer for different operating conditions at position B (30 mm downstream from the junction).

\section{Conclusions}

Micromixer is a fundamental aspect of fluid manipulation is microfluidic systems. Various active and passive micromixing principles have been proposed to increase the mixing performance of the system. In this paper, a laser-fabricated Dean micromixer was presented, and its mixing performance then compared with well-known Y-and Tmicromixers at different Reynolds number from $R e=5$ to $R e=100$. In addition, ultrasound and thermal energy were applied extraneously and their effect toward mixing performance were also investigated. All three micromixers show relatively higher mixing indexes at lower Reynolds numbers, which is attributed to increased molecular diffusion due to higher residence time. T-micromixer demonstrates marginally higher mixing performance as compared to $Y$ - and Dean micromixers for $5 \leq \operatorname{Re} \leq 20$. The Dean micromixer exhibits higher mixing performance (about $27 \%$ better) as compared to $\mathrm{T}$ - and $\mathrm{Y}$ - micromixers for 
$40 \leq \operatorname{Re} \leq 100$. The highest mixing index for varying Reynolds number $(5 \leq \operatorname{Re} \leq 100)$ can be attained under the influence of both ultrasound and thermal energies. This may be attributed to the formation of strong micro-jets and micro-streams caused by the collapse of microbubbles due to cavitation developed from the ultrasonic wave propagation (sonication). It can be observed that the ultrasound and thermal effects toward mixing performance is more significant at $5 \leq \operatorname{Re} \leq 20$ because of prolonged mechanical effect within the system. It is also found that the mixing index increases of about $6 \%$ to $10 \%$ at various Reynolds numbers once the sonicated mixing fluids were heated from $30{ }^{\circ} \mathrm{C}$ to $60^{\circ} \mathrm{C}$. The temperature increases reduce fluids viscosity, thereby allowing the Dean vortices to retain their hydrodynamic identity longer for enhanced molecular diffusion.

Author Contributions: Conceptualization, F.M. and K.F.T.; investigation, F.M. and K.F.T.; Formal analysis, F.M. and K.F.T.; software, F.M.; supervision, K.F.T.; funding acquisition, S.M. and N.W.; writing-original draft preparation, F.M.; and writing—review and editing, K.F.T., S.M. and N.W.; All authors have read and agreed to the published version of the manuscript.

Funding: The authors are grateful to the Universiti Malaysia Sarawak for the Grant No. F02/PGRG/ 2043/2020 allocated to the project.

Institutional Review Board Statement: Not applicable.

Informed Consent Statement: Not applicable.

Data Availability Statement: Not applicable.

Conflicts of Interest: The authors declare no conflict of interest.

\section{References}

1. Hou, X.; Zhang, Y.S.; Trujillo-de Santiago, G.; Alvarez, M.M.; Ribas, J.; Jonas, S.J.; Weiss, P.S.; Andrews, A.M.; Aizenberg, J.; Khademhosseini, A. Interplay between materials and microfluidics. Nat. Rev. Mater. 2017, 2, 17016. [CrossRef]

2. Ward, K.; Fan, Z.H. Mixing in microfluidic devices and enhancement methods. J. Micromech. Microeng. $2015,25,094001$. [CrossRef] [PubMed]

3. Tamrin, K.; Rahmatullah, B.; Samuri, S. An experimental investigation of three-dimensional particle aggregation using digital holographic microscopy. Opt. Lasers Eng. 2015, 68, 93-103. [CrossRef]

4. Nguyen, N.-T.; Wu, Z. Micromixers-A review. J. Micromech. Microeng. 2004, 15, R1. [CrossRef]

5. Mahmud, F.; Tamrin, K.F.; Sheikh, N.A. A Review of Enhanced Micromixing Techniques in Microfluidics for the Application in Wastewater Analysis. In Advances in Waste Processing Technology; Springer Science and Business Media LLC: Berlin/Heidelberg, Germany, 2020; pp. 1-22.

6. Hessel, V.; Löwe, H.; Schönfeld, F. Micromixers-A review on passive and active mixing principles. Chem. Eng. Sci. 2005, 60, 2479-2501. [CrossRef]

7. Faryadi, M.; Rahimi, M.; Safari, S.; Moradi, N. Effect of high frequency ultrasound on micromixing efficiency in microchannels. Chem. Eng. Process. Process Intensif. 2014, 77, 13-21. [CrossRef]

8. Aljbour, S.; Yamada, H.; Tagawa, T. Ultrasound-assisted phase transfer catalysis in a capillary microreactor. Chem. Eng. Process. Process Intensif. 2009, 48, 1167-1172. [CrossRef]

9. Yang, Z.; Matsumoto, S.; Goto, H.; Matsumoto, M.; Maeda, R. Ultrasonic micromixer for microfluidic systems. Sens. Actuators A Phys. 2001, 93, 266-272. [CrossRef]

10. Shamsoddini, R. SPH investigation of the thermal effects on the fluid mixing in a microchannel with rotating stirrers. Fluid Dyn. Res. 2017, 50, 025509. [CrossRef]

11. Xu, B.; Wong, T.N.; Nguyen, N.-T. Experimental and numerical investigation of thermal chaotic mixing in a T-shaped microchannel. Heat Mass Transf. 2011, 47, 1331-1339. [CrossRef]

12. Ringkai, H.; Tamrin, K.; Sheikh, N.; Barroy, P. Characterization of dissimilar liquids mixing in T-junction and offset T-junction microchannels. Proc. Inst. Mech. Eng. Part E J. Process. Mech. Eng. 2021. [CrossRef]

13. Le The, H.; Ta, B.Q.; Le Thanh, H.; Dong, T.; Thoi, T.N.; Karlsen, F. Geometric effects on mixing performance in a novel passive micromixer with trapezoidal-zigzag channels. J. Micromech. Microeng. 2015, 25, 094004. [CrossRef]

14. You, J.B.; Kang, K.; Tran, T.T.; Park, H.; Hwang, W.R.; Kim, J.M.; Im, S.G. PDMS-based turbulent microfluidic mixer. Lab Chip 2015, 15, 1727-1735. [CrossRef]

15. Chen, X.; Li, T.; Zeng, H.; Hu, Z.; Fu, B. Numerical and experimental investigation on micromixers with serpentine microchannels. Int. J. Heat Mass Transf. 2016, 98, 131-140. [CrossRef]

16. Scherr, T.; Quitadamo, C.; Tesvich, P.; Park, D.S.-W.; Tiersch, T.; Hayes, D.; Choi, J.-W.; Nandakumar, K.; Monroe, W.T. A planar microfluidic mixer based on logarithmic spirals. J. Micromech. Microeng. 2012, 22, 055019. [CrossRef] [PubMed] 
17. Shah, I.; Kim, S.W.; Kim, K.; Doh, Y.H.; Choi, K.H. Experimental and numerical analysis of Y-shaped split and recombination micro-mixer with different mixing units. Chem. Eng. J. 2019, 358, 691-706. [CrossRef]

18. Chen, X.; Shen, J.; Hu, Z. Fabrication and performance evaluation of two multi-layer passive micromixers. Sens. Rev. 2018, 38, 321-325. [CrossRef]

19. Parsa, M.K.; Hormozi, F.; Jafari, D. Mixing enhancement in a passive micromixer with convergent-divergent sinusoidal microchannels and different ratio of amplitude to wave length. Comput. Fluids 2014, 105, 82-90. [CrossRef]

20. Ansari, M.A.; Kim, K.-Y.; Anwar, K.; Kim, S.M. A novel passive micromixer based on unbalanced splits and collisions of fluid streams. J. Micromech. Microeng. 2010, 20, 55007-55018. [CrossRef]

21. Kumar, V.; Paraschivoiu, M.; Nigam, K. Single-phase fluid flow and mixing in microchannels. Chem. Eng. Sci. 2011, 66, 1329-1373. [CrossRef]

22. Zhu, G.-P.; Nguyen, N.-T. Rapid magnetofluidic mixing in a uniform magnetic field. Lab Chip 2012, 12, 4772-4780. [CrossRef] [PubMed]

23. Ji, H.M.; Samper, V.; Chen, Y.; Hui, W.C.; Lye, H.J.; Mustafa, F.B.; Lee, A.C.; Cong, L.; Heng, C.K.; Lim, T.M. DNA purification silicon chip. Sens. Actuators A Phys. 2007, 139, 139-144. [CrossRef]

24. Kastania, A.S.; Tsougeni, K.; Papadakis, G.; Gizeli, E.; Kokkoris, G.; Tserepi, A.; Gogolides, E. Plasma micro-nanotextured polymeric micromixer for DNA purification with high efficiency and dynamic range. Anal. Chim. Acta 2016, 942, 58-67. [CrossRef] [PubMed]

25. Shanko, E.-S.; Van De Burgt, Y.; Anderson, P.D.; Toonder, J.M.J.D. Microfluidic Magnetic Mixing at Low Reynolds Numbers and in Stagnant Fluids. Micromachines 2019, 10, 731. [CrossRef]

26. Luong, T.-D.; Phan, V.-N.; Nguyen, N.-T. High-throughput micromixers based on acoustic streaming induced by surface acoustic wave. Microfluid. Nanofluid. 2010, 10, 619-625. [CrossRef]

27. Yaralioglu, G.G.; Wygant, I.O.; Marentis, T.C.; Khuri-Yakub, B.T. Ultrasonic Mixing in Microfluidic Channels Using Integrated Transducers. Anal. Chem. 2004, 76, 3694-3698. [CrossRef] [PubMed]

28. Bezagu, M.; Arseniyadis, S.; Cossy, J.; Couture, O.; Tanter, M.; Monti, F.; Tabeling, P. A fast and switchable microfluidic mixer based on ultrasound-induced vaporization of perfluorocarbon. Lab Chip 2015, 15, 2025-2029. [CrossRef]

29. Ahmed, D.; Mao, X.; Juluri, B.K.; Huang, T.J. A fast microfluidic mixer based on acoustically driven sidewall-trapped microbubbles. Microfluid. Nanofluid. 2009, 7,727-731. [CrossRef]

30. Meng, J.; Li, S.; Li, J.; Yu, C.; Wei, C.; Dai, S. AC electrothermal mixing for high conductive biofluids by arc-electrodes. J. Micromech. Microeng. 2018, 28, 065004. [CrossRef]

31. Huang, K.-R.; Chang, J.-S.; Chao, S.D.; Wung, T.-S.; Wu, K.-C. Study of active micromixer driven by electrothermal force. Jpn. J. Appl. Phys. 2012, 51, 047002. [CrossRef]

32. Parvizian, F.; Rahimi, M.; Faryadi, M. Macro and micromixing in a novel sonochemical reactor using high frequency ultrasound. Chem. Eng. Process. Process Intensif. 2011, 50, 732-740. [CrossRef]

33. Le The, H.; Le Thanh, H.; Dong, T.; Ta, B.Q.; Tran-Minh, N.; Karlsen, F. An effective passive micromixer with shifted trapezoidal blades using wide Reynolds number range. Chem. Eng. Res. Des. 2015, 93, 1-11. [CrossRef]

34. Sivashankar, S.; Agambayev, S.; Mashraei, Y.; Li, E.Q.; Thoroddsen, S.T.; Salama, K.N. A “twisted" microfluidic mixer suitable for a wide range of flow rate applications. Biomicrofluidics 2016, 10, 034120. [CrossRef]

35. Fu, H.; Liu, X.; Li, S. Mixing indexes considering the combination of mean and dispersion information from intensity images for the performance estimation of micromixing. RSC Adv. 2017, 7, 10906-10914. [CrossRef]

36. Mahmud, F.; Tamrin, K.F. Method for determining mixing index in microfluidics by RGB color model. Asia Pac. J. Chem. Eng. 2020, 15, e2407. [CrossRef]

37. Nimafar, M.; Viktorov, V.; Martinelli, M. Experimental comparative mixing performance of passive micromixers with H-shaped sub-channels. Chem. Eng. Sci. 2012, 76, 37-44. [CrossRef]

38. Hossain, S.; Lee, I.; Kim, S.M.; Kim, K.-Y. A micromixer with two-layer serpentine crossing channels having excellent mixing performance at low Reynolds numbers. Chem. Eng. J. 2017, 327, 268-277. [CrossRef]

39. Chen, X.; Li, T.; Gao, Q. A novel method for rapid fabrication of pmma microfluidic chip by laser cutting and sealing integration. Surf. Rev. Lett. 2019, 26, 1950042. [CrossRef]

40. Faustino, V.; Catarino, S.O.; Lima, R.; Minas, G. Biomedical microfluidic devices by using low-cost fabrication techniques: A review. J. Biomech. 2016, 49, 2280-2292. [CrossRef]

41. Catarino, S.O.; Rodrigues, R.O.; Pinho, D.; Miranda, J.M.; Minas, G.; Lima, R. Blood Cells Separation and Sorting Techniques of Passive Microfluidic Devices: From Fabrication to Applications. Micromachines 2019, 10, 593. [CrossRef]

42. Lin, C.-H.; Fu, L.-M.; Chien, Y.-S. Microfluidic T-Form Mixer Utilizing Switching Electroosmotic Flow. Anal. Chem. 2004, 76, 5265-5272. [CrossRef]

43. Sarkar, S.; Singh, K.; Shankar, V.; Shenoy, K. Numerical simulation of mixing at 1-1 and 1-2 microfluidic junctions. Chem. Eng. Process. Process Intensif. 2014, 85, 227-240. [CrossRef]

44. Matsunaga, T.; Lee, H.-J.; Nishino, K. An approach for accurate simulation of liquid mixing in a T-shaped micromixer. Lab Chip 2013, 13, 1515. [CrossRef] [PubMed]

45. Galletti, C.; Roudgar, M.; Brunazzi, E.; Mauri, R. Effect of inlet conditions on the engulfment pattern in a T-shaped micro-mixer. Chem. Eng. J. 2012, 185, 300-313. [CrossRef] 
46. Rudyak, V.; Minakov, A. Modeling and Optimization of Y-Type Micromixers. Micromachines 2014, 5, 886-912. [CrossRef]

47. Di Carlo, D. Inertial microfluidics. Lab Chip 2009, 9, 3038-3046. [CrossRef]

48. Seip, R.; Ebbini, E. Noninvasive estimation of tissue temperature response to heating fields using diagnostic ultrasound. IEEE Trans. Biomed. Eng. 1995, 42, 828-839. [CrossRef] [PubMed]

49. Sutkar, V.S.; Gogate, P.R. Mapping of cavitational activity in high frequency sonochemical reactor. Chem. Eng. J. 2010, 158, 296-304. [CrossRef]

50. Rahimi, M.; Azimi, N.; Parvizian, F. Using microparticles to enhance micromixing in a high frequency continuous flow sonoreactor. Chem. Eng. Process. Process Intensif. 2013, 70, 250-258. [CrossRef] 